\title{
Tecnologia e campos disciplinares: os citotécnicos e a implementação do teste de Papanicolaou no Brasil
}

\author{
Luiz Antonio Teixeira (*) y Leticia Pumar (**) \\ (*) Casa de Oswaldo Cruz / Fiocruz, Rio de Janeiro. \\ teixeira@fiocruz.br \\ (**) Casa de Oswaldo Cruz / Fiocruz, Rio de Janeiro. \\ leticiapumar@gmail.com
}

Dynamis

[0211-9536] 2014; $34(1): 49-72$

Fecha de recepción: 27 de septiembre de 2012

http://dx.doi.org/10.4321/S0211-95362014000100004

Fecha de aceptación: 17 de julio de 2013

SUMÁRIO: 1.—Introdução. 2.-A ferramenta adequada para o trabalho. 3.—O programa nacional de screening. 4.-O citotécnico entre o público e o privado. 5.-Disputas pela supervisão do trabalho. 6.-Qual o grupo certo para o trabalho? 7.-Citotécnicos: um grupo em mobilização. 8.-Considerações finais.

RESUMO: A apropriação e utilização do teste de Papanicolaou como tecnologia fundamental para o controle do câncer de colo do útero no Brasil foi fruto de escolhas, acordos e embates entre determinados grupos profissionais (médicos de diferentes especialidades, farmacêuticos, biólogos, biomédicos e citotécnicos). Na primeira parte do trabalho apresentamos o processo de formulação das primeiras campanhas de rastreamento populacional com uso do teste Papanicolaou no país e, consequentemente, o surgimento da profissão de citotécnicos (profissionais dedicados a leitura das lâminas de Papanicolaou). Num segundo momento, partimos de algumas questões levantadas pela historiografia internacional no campo da história das ciências e das técnicas para discutimos as peculiaridades do processo de apropriação do teste Papanicolaou no contexto brasileiro. Priorizamos as questões relativas aos debates entre diferentes grupos profissionais envolvidos com a lógica desse exame e às relações entre os setores públicos e privados de saúde. Demonstramos que as visões distintas sobre essa tecnologia no campo de diferentes disciplinas e a relação destas com a dinâmica do mercado de trabalho moldam a trajetória da profissão de citotécnico e a forma como o teste de Papanicolaou foi (e está sendo) apropriado como tecnologia central para o rastreio do câncer de colo do útero no Brasil.

PALABRAS CLAVE: história do controle do câncer de colo do útero, história das ciências e das técnicas, teste de Papanicolaou, citotécnicos.

KEY WORDS: history of cervical cancer control, history of sciences and technologies, Pap smear, cytotechnicians/cytotechnologist. 


\section{Introdução $(*)$}

Diversos trabalhos analisaram a maneira pela qual o teste de Papanicolaou passou a ser visto como a tecnologia adequada para o controle do câncer cervical (right tool for the job) e quais os custos e benefícios da utilização dessa tecnologia. Tais estudos relativizam a ideia de que o rastreio populacional com o uso do teste de Papanicolaou foi a única forma possível de prevenção do câncer cervical e demonstram que a aplicação dessa tecnologia ocorreu de forma diferente em cada contexto local ${ }^{1}$. Ao seguir essa perspectiva, esses trabalhos ampliam o campo de análise sobre as técnicas de controle da doença e inserem o desenvolvimento do teste Papanicolaou no âmbito de um conjunto de alternativas possíveis, demonstrando que a compreensão do teste como «righ tool for the job» é resultado de escolhas de alguns grupos em determinados contextos sócio-históricos.

Partindo dessas reflexões, esse artigo analisa algumas particularidades da aplicação dessa tecnologia no Brasil, tendo como foco o surgimento do citotécnico e as controvérsias atinentes ao processo de regulamentação da extensão de suas atividades. Como em grande parte dos países ocidentais, no Brasil o citotécnico é um profissional que tem como principal função examinar as lâminas elaboradas a partir do material colhido e encaminhar os casos considerados atípicos para avaliação do médico citopatologista. Dessa forma, é o responsável pela triagem do material citopatológico, permitindo que o médico examine somente os casos suspeitos, em geral 10 a

(*) Pesquisa elaborada na Casa de Oswaldo Cruz (Fiocruz), no âmbito do projeto História do Câncer - atores, cenários e políticas públicas. Contamos com recursos do Programa Estratégico de Apoio à Pesquisa em Saúde (Papes/Fiocruz) e da Fundação Câncer.

1. A frase grifada intitula o clássico artigo de Monica Casper e Adele Clark sobre a estabilização do pap smear como tecnologia adequada ao controle do câncer cervical: Casper, Monica; Clarke, Adele. Making the Pap Smear into the «Right Tool» for the Job: Cervical cancer screening in the USA, circa 1940-95. Social Studies of Sciences. 1998; 28 (2): 255-290. Ver também: Lowy, Ilana. Cancer, women, and public health: the history of screening for cervical cancer. História, Ciencia, Saude-Manguinhos. 2010; 17 (suppl. 1): 53-67. Um exemplo da importância do contexto local na especificidade do desenvolvimento do Papanicolaou refere-se a trajetória peculiar do controle do câncer cervical no Brasil e na Argentina, aonde o uso da colposcopia como primeiro exame para a prevenção da doença perdurou até a década 1960, diferente do que ocorreu nos EUA e na Europa. Eraso, Yolanda. Migrating techniques, multiplying diagnoses: The contribution of Argentina and Brazil to early «detection policy» in cervical cancer. História, Ciências, Saúde-Manguinhos. 2010; 17 (suppl. 1): 33-51 e Teixeira, Luiz; Lowy, Ilana. Imperfect tools for a difficult job: Colposcopy, «colpocytology» and screening for cervical cancer in Brazil. Social Studies of Science. 2011; 41 (4): 585-608. 
30\% do total. Seu trabalho, se tornou cada vez mais necessário a medida que o uso do Papanicolaou se intensificou no país.

No final da década de 1960, ocorreu uma transformação nas ações para o controle do câncer cervical no Brasil. O modelo centrado no uso combinado da colposcopia e da citologia, começou a dar lugar a campanhas ou programas públicos de prevenção baseados no screening com o uso do Papanicolaou. A ampliação do volume de exames criou a necessidade de aumentar o número de profissionais para a leitura das lâminas citológicas, que até então era realizada na maioria das vezes por médicos residentes ou por citopatologistas. Nesse contexto, o citotécnico passou a ser visto como um elemento fundamental para a ampliação de programas de controle da doença e surgiram os primeiros cursos para a formação desse profissional e iniciativas para a normatização da profissão. No entanto, o processo de reconhecimento da profissão, com a padronização de sua formação e a regulamentação da categoria profissional, ainda hoje está inconcluso, sendo alvo de longos debates ${ }^{2}$.

Em trabalho anterior, discutimos a trajetória da formação dos citotécnicos no país, relacionando o surgimento dos cursos para a sua formação ao movimento de expansão de programas e campanhas de rastreamento do câncer cervical na Brasil. A partir da perspectiva da sociologia das profissões, procuramos mostrar como a análise de suas atividades não pode se prender somente a sua formação, se relacionando também ao perfil do mercado de trabalho e a suas formas de organização ${ }^{3}$. A partir desse estudo foi possível perceber que a iniciativa de regulamentação do trabalho desse grupo de técnicos responsáveis pela triagem do material citopatológico, esbarra nas discussões entre biólogos, farmacêuticos, biomédicos e médicos citopatologistas sobre quem tem a capacitação técnica para realizar a análise das lâminas e supervisionar essa atividade, garantindo a qualidade dos exames efetuados. Os citopatologistas, representados pela Sociedade Brasileira de Citopatologia, afirmam que todo diagnóstico citopatologico deve ser dado por um médico da especialidade, pois a realização de qualquer diagnóstico

2. Teixeira, Luiz; Porto, Marco; Pumar, Leticia. A expansão do rastreio do câncer do colo do útero e a formação de citotécnicos no Brasil. Physis. 2012; 22 (2): 713-731.

3. Teixeira; Porto; Pumar, n. 2, p. 713-731. Sobre a sociologia das profissões ver, em particular: Freidson, E. Profissão médica. Um estudo de sociologia do conhecimento aplicado. São Paulo: Unesp; 2009, e Abbott, A. The system of professions: An essay on the division of expert labor. Chicago: the University of Chicago Press; 1988. 
caberia apenas aos médicos. No campo oposto, os biólogos, farmacêuticos e biomédicos afirmam que o Papanicolaou é «um método de screnning» e que os resultados das leituras das lâminas estão fora do campo de ação dos médicos, caracterizando-se como «laudos técnicos» para embasar diagnósticos médicos posteriores.

Nosso objetivo agora é avaliar a ação dos diversos grupos profissionais pelo monopólio do trabalho de leitura e emissão de laudos citológicos e como elas se relacionam às especificidades da utilização do Papanicolaou no país. Para tanto, tomamos por base a perspectiva da história das ciências e das tecnologias de que "tools", "jobs", and the "rightness" of the tools for the jobs are each and all situationally constructed»". Seguindo as reflexões de Clarke e Fujimura sobre «how tools shape disciplines and how disciplines shapes tools», nossa análise mostrará que, nos debates entre esses diferentes campos disciplinares, as ambiguidades da tecnologia são acionadas de diferentes maneiras pelos grupos que procuram participar das ações de controle do câncer cervical no Brasil. Esse embate também encontra-se crivado pelas distintas posições ocupadas pelos citotécnicos no campo da saúde pública e da medicina privada, o que dificulta ainda mais a padronização da formação e a regulamentação da profissão de citotécnico no Brasil.

$\mathrm{Na}$ primeira parte do artigo mostraremos como o Papanicolaou transformou-se na «ferramenta» certa para o controle do câncer de colo no Brasil e, nesse contexto, como os citotécnicos tornaram-se elementos chaves para as campanhas de screening efetuadas a partir da década de 1970. Em seguida nos voltaremos para a criação do Programa Nacional de Screening Viva Mulher, observando sua importância na intensificação da utilização do Papanicolaou. Nas duas seções seguintes avaliamos como, nesse contexto, o desenvolvimento dos laboratórios públicos e privados impulsionaram a profissionalização dos citotécnicos e os debates sobre a capacidade técnica para a leitura (e supervisão desta) das lâminas. As duas últimas seções analisam os embates em torno da busca de monopólio da leitura de lâminas citológicas travadas entre diferentes profissões no campo da saúde, a mobilização dos citotécnicos e as iniciativas estatais de normatização dessa atividade até a primeira década deste século.

4. Clarke, Adele; Fujimura, Joan, eds. The right tools for the job: at work in twentieth-century life sciences. Princeton: Princeton University Press; 1992, p. 5. 


\section{A ferramenta adequada para o trabalho}

Nas décadas de 1940 e 1950, as ações para a detecção precoce do câncer de colo do útero era realizada em consultórios particulares, em serviços de ginecologia de alguns poucos hospitais públicos ou filantrópicos e em ambulatórios ginecológicos ligados a universidades e instituições não governamentais. Muitos desses serviços utilizavam o modelo triplo ${ }^{5}$, ou seja, faziam uso combinado da colposcopia e da citologia como testes iniciais e da biopsia como forma de confirmação da natureza das alterações observadas nos exames iniciais. A partir dos anos 1960, esse modelo começou a conviver com iniciativas de prevenção baseados principalmente na citologia, sendo a colposcopia e a biópsia utilizadas somente como exames complementares, em caso de observação de anomalias no Papanicolaou ${ }^{6}$.

Em meados dos anos 1960, começaram a surgir campanhas de rastreamento em massa do câncer cervical no Brasil. Seguindo as diretrizes propostas pela Organização Pan-americana de Saúde (OPAS) foram realizadas campanhas de rastreamento nos Estados do Rio Grande do Sul, Bahia e São Paulo. A partir do início da década de 1970, várias campanhas foram desenvolvidas na região sudeste, em especial no Estado de São Paulo por entidades filantrópicas e governos locais. Em 1973, com a criação do Programa Nacional de Combate ao Câncer, o Ministério da Saúde passou a incentivar financeiramente a elaboração de campanhas de rastreamento em diversos Estados. Esse processo marcou uma profunda transformação no controle do câncer cervical no Brasil, que deixou de ser feito exclusivamente no âmbito dos consultórios particulares, hospitais especializados e gabinetes ginecológicos e paulatinamente se transformou numa responsabilidade referente à saúde pública ${ }^{7}$.

A partir da ampliação do uso da citologia, a leitura das lâminas de exames citológicos se tornou uma atividade central à saúde pública e a ideia de se formar técnicos para a realização da triagem desse material

5. Teixeira e Lowy denominaram de modelo triplo o uso combinado da colposcopia, citologia e biopsia nos exames preventivos do câncer de colo. O trabalho mostra como essa forma de utilização das técnicas se desenvolveu no Brasil entre os anos 1940 e 1970, ressaltando sua originalidade frente a grande parte dos países ocidentais que utilizaram a colposcopia como exame complementar ao Papanicolaou. Teixeira; Lowy, n. 1, p. 585-608.

6. Teixeira; Lowy, n. 1, p. 585-608.

7. Teixeira, Luiz; Porto, Marco. O câncer no Brasil: passado e presente. Rio de Janeiro: Outras Letras; 2012. 
surgiu como resposta para a grande demanda de profissionais capacitados para essa atividade. Inicialmente, a formação desses técnicos era realizada informalmente pelos próprios médicos nos laboratórios de universidade e instituições de pesquisa. Logo, começaram a surgir iniciativas de criação de cursos para formação desses profissionais. O primeiro curso para a formação de citotécnicos de que temos notícia no Brasil foi instituído em 1968, no Centro de Pesquisa Luiza Gomes de Lemos, no Rio de Janeiro. Esse centro tinha sido criado pelo presidente brasileiro Juscelino Kubitschek (presidente entre 1956 e 1961), após a morte de sua sogra, Luiza Gomes de Lemos, em decorrência de um câncer uterino. $\mathrm{O}$ curso tinha a duração de dois anos e funcionava em regime de horário integral. O currículo era amplo e o aluno assistia aulas teóricas e práticas sobre citologia ginecológica e sobre outras aplicações da citologia, como a citologia pulmonar. O único pré-requisito para o ingresso no curso era o candidato ter terminado o ensino médio ${ }^{8}$.

Em 1973, outro curso de formação de citotécnicos surgiu no Instituto Brasileiro de Pesquisas em Oncologia e Obstetrícia (IBEPOG), no Estado de São Paulo. Foi criado para apoiar a expansão das campanhas de screening efetuadas na cidade de São Paulo para outras regiões do Estado. A instituição recrutou portadores de necessidades especiais como clientela preferencial de seus cursos, pois os organizadores aliavam à busca de inserção dessas pessoas no mercado de trabalho, a ideia de que a dificuldade de locomoção dos cadeirantes lhes proporcionaria mais eficiência no cansativo trabalho de análise de lâminas ao microscópico. O curso do IBEPOG também tinha currículo teórico e prático amplo e voltado para pessoal de nível médio 9 .

Durante a primeira metade da década de 1970, o número de centros formadores de citotécnicos se ampliou. Em 1975 já existiam quatro centros de treinamento no âmbito do Ministério da Saúde: Centro de Citodiagnóstico (FUSAM/PE), Laboratório de Anatomia Patológica da Secretaria de Saúde do Rio Grande do Sul, Instituto Nacional de Câncer e Instituto Brasileiro de Controle do Câncer/SP (CUNHA, 1978). Além deles, muitas instituições de saúde ligadas a Secretarias de saúde estaduais, centros universitários e

8. Barcelos, José. Introdução. In: Campos da Paz Filho, Athur; Barcelos, Jose. Concursos de especialização em citopatologia. Rio de Janeiro: Escola de Citopatologia do Centro de Pesquisas Luiza Gomes de Lemos / Fundação Pioneiras Sociais; 1974, p. 5-7.

9. Capucci, F. Filosofia Sampaio Góes: Instituto Brasileiro de Controle do Câncer - IBCC 35 anos. São Paulo: Activa Comunicação; 2003. 
fundações filantrópicas passaram a efetuar treinamento de citotécnicos ${ }^{10}$. No entanto, muitos citotécnicos ainda aprendiam a atividade informalmente nos laboratórios privados. Em relação à padronização da formação dos citotécnicos, as iniciativas estatais mostram a existência de várias proposições, configurando diferentes formas de ver a mesma atividade. De um lado, existia o modelo de curso de longa duração e de formação ampliada, do Centro de Pesquisa Luiza Gomes de Lemos e do IBEPOG. Por outro lado, surgiram em outros estados cursos mais curtos, com currículos restritos, direcionados especificamente ao aprendizado prático da leitura do teste Papanicolaou. Além disso, alguns profissionais defendiam a criação de cursos profissionalizantes no âmbito do ensino regular. Essas diferentes visões sobre os cursos demonstram diferentes formas de pensar a extensão do trabalho do citotécnico ${ }^{11}$.

As iniciativas visando a regulamentação da formação do trabalho dos citotécnicos no país também se iniciam partir de 1970. A primeira delas foi a criação, em 1973, do concurso para a concessão de um «certificado de suficiência em citotecnologia», promovido pela Sociedade Brasileira de Citologia (SBC). Essa Sociedade, criada em 1956, teve um importante papel na busca pelo reconhecimento da citopatologia como especialidade médica. A criação desse certificado pela SBC colocava os citotécnicos sob a tutela dos médicos especialistas em citopatologia e foi a primeira ação no sentido de definir as qualificações necessária para o bom cumprimento de suas funções ${ }^{12}$. Outra iniciativa relevante foi a tentativa do Ministério da Saúde de incluir a formação dos citotecnicos no âmbito do ensino profissionalizante, com a elaboração de uma proposta de habilitação e de currículo mínimo para a formação desse profissional. Embora essa proposta não tenha se concretizado, ela deu origem a um parecer oficial, publicado em abril

10. Além das instituições já citadas, atuavam na formação de citotécnicos nesse período o Instituto Nacional de Câncer, no Rio de Janeiro; a Santa Casa da Misericórdia de São Paulo; a Faculdade de Medicina da Universidade Estadual de Campinas; o Centro de Treinamento de Recursos Humanos da Fundação Amaury de Medeiros, da Secretaria de Saúde do Estado de Pernambuco; a Faculdade de Medicina da Universidade Católica de Porto Alegre; o Instituto do Câncer de Londrina; a Secretaria de Saúde do Estado de Minas Gerais e a Secretaria de Saúde do Estado da Bahia. Barcelos, n. 8, p. 6-7.

11. Teixeira; Porto; Pumar, n. 2, p. 713-731.

12. Barcelos, n. 8, p. 7. 
de 1989, pelo Ministério da Educação e Cultura, que definiu os conteúdos curriculares mínimos e as atribuições dos citotécnicos ${ }^{13}$.

Apesar dos debates e iniciativas relacionados à necessidade de padronização da formação dos citotécnicos para a manutenção das estratégias de prevenção do câncer cervical, a regulamentação de sua formação e atuação profissional não ocorreu. As campanhas de screening e os incentivos governamentais não foram suficientes para criar consenso em torno da formação destes profissionais. Nas décadas seguintes, esse problema iria se ampliar com o desenvolvimento de campanhas nacionais de prevenção.

\section{O programa nacional de screening}

O surgimento de um programa nacional de controle do câncer de colo do útero só se tornou possível após a criação de um sistema universal de saúde no Brasil. Até o final dos anos 1980, o país conviveu com um sistema de saúde subdividido em dois diferentes setores: um sistema de saúde pública, dedicado prioritariamente a ações no campo do saneamento, vacinação, e controle de doenças transmissíveis; e um sistema de medicina previdenciária (seguro saúde estatal) originalmente dirigido aos grupos trabalhadores urbanos, mas que, a partir da década de 1960, começou a ampliar sua cobertura para diversos grupos que não contribuíam para seu financiamento. A partir de 1964, o país passou por uma forte ditadura, de inspiração econômica liberal, que valorizou o sistema privado de saúde em detrimento das ações públicas. Nesse contexto, o Estado ampliou fortemente a contratação de serviços privados dirigidos aos cidadãos cobertos pela medicina previdenciária. Essa diretriz reforçou a medicina curativa de base hospitalar em detrimento das ações preventivas de saúde pública ${ }^{14}$.

Somente a partir de meados dos anos 1980, no processo de redemocratização da sociedade, as propostas de reforma na saúde, que acabaram dando origem a um sistema único e universal de saúde, começam a se desenvolver. Tendo na base de seu projeto a busca pela ampliação da cobertura e a racionalização do sistema e também se preocupando com a

13. Parecer n. 353/89. Brasília: Ministério da Educação; 1989.

14. Escorel, Sarah; Nascimento, Dilene; Edler, Flavio. As origens da reforma sanitária e do SUS. In: Lima, Nisia; Gershman, Silvia; Edler, Flavio; Suárez, Julio. Saúde e democracia: história e perspectivas do SUS. Rio de Janeiro: FIOCRUZ; 2005, p. 59-83. 
atenção primária e com as ações preventivas - aspectos fortemente recomendados pelas agencias multilaterais de saúde a partir dos anos 1970 - um movimento social liderado por sanitaristas pôs em marcha uma reforma sanitária. Em 1988, no processo de elaboração de uma nova constituição para o país, foram estipuladas as bases do atual sistema universal de saúde (SUS), consolidado em lei dois anos depois ${ }^{15}$.

Sob um novo contexto político democrático e um sistema de saúde universal, surgiriam as primeiras iniciativas nacionais para o controle do câncer de colo do útero ${ }^{16}$. A partir da reforma sanitária, o Instituto Nacional do Câncer passou a se responsabilizar pela coordenação da política de controle do câncer no país. Em 1995, como consequência das demandas do movimento feminista, reforçadas pela participação do Brasil na VI Conferência Internacional da Mulher, o Ministério da Saúde incumbiuo Instituto Nacional de Câncer de responsabilidade de formulação e implantação de um programa de controle do câncer do colo do útero. O Programa, então denominado Viva Mulher, implantou projetos-piloto em um município de cada região brasileira, rastreando mulheres entre 35 e 49 anos. Em 1998, o projeto foi transferido para o Ministério da Saúde, se transformando em um programa nacional para a realização de exames citológicos que visava também garantir o acompanhamento e tratamento das mulheres com citologia positiva. Em sua primeira campanha, o Viva Mulher (1988) conseguiu examinar mais de 3 milhões de mulheres, mobilizando quase a totalidade dos municípios brasileiros. No ano seguinte transformou-se em um programa permanente que busca rastrear todas as brasileiras em idade de maior risco e também proceder ao seguimento e tratamento das que apresentassem lesões precursoras ${ }^{17}$.

15. Sob o processo que deu origem a reforma sanitária ver: Escorel, Sarah; Nascimento, Dilene; Edler, Flavio. As origens da reforma sanitária e do SUS. In: Lima, Nisia; Gershman, Silvia; Edler, Flavio; Suárez, Julio. Saúde e democracia: história e perspectivas do SUS. Rio de Janeiro: FIOCRUZ; 2005; p. 59-83.

16. Em 1987, antes mesmo da criação do SUS, o governo federal criou um programa, denominado PRO-ONCO, que era direcionado a diversos tipos de câncer. No entanto, a falta de integração entre os setores previdenciário e de saúde pública foi um impeditivo ao seu maior desenvolvimento.

17. A partir de 1999, o Viva Mulher passou a oferecer exames citológicos de rotina, acompanhados de grandes campanhas trienais. Em 2002, foi realizada a segunda campanha nacional, a partir de então o programa passou a dar ênfase ao aperfeiçoamento da rede de atenção oncológica. Teixeira, Porto, Pumar, n. 2, p. 713-731. 
O surgimento do Viva Mulher foi um marco no controle do câncer de colo de útero no país, pois possibilitou uma forte ampliação da utilização do teste Papanicolaou, numa ação coordenada e de âmbito nacional. Além disso, permitiu a padronização de procedimentos e fortaleceu a noção de prevenção da doença a partir de grandes campanhas publicitárias dirigidas às mulheres. No entanto, mais do que soluções rápidas, o desenvolvimento do programa gerou novas dificuldades e questões. As principais se relacionaram à capacidade do sistema de saúde para acompanhar as mulheres com lesões precursoras detectadas, à eficiência para prover acesso ao exame às populações de áreas mais pobres ou geograficamente isoladas e à qualidade dos exames. Os primeiros problemas eram decorrência das deficiências do recém-criado sistema único de saúde brasileiro e fogem aos interesses desse estudo, já o último se relacionava a escassez de profissionais treinados para a leitura das lâminas e da inexistência de laboratórios adequados para essa atividade, aspectos fortemente relacionados à questão mais geral da normatização do trabalho dos citotécnicos. Uma análise das limitações e alcance do Programa Viva Mulher encontra-se no texto de Habib e Porto nesse mesmo dossiê.

\section{O citotécnico entre o público e o privado}

A partir das primeiras campanhas públicas de screening, realizadas ainda na década de 1970, o Ministério da Saúde passou a comprar serviços de citologia de laboratórios privados. Esse sistema funcionava em consonância com o modelo de saúde pública de favorecimento à contratação de serviços privados pela previdência oficial que vinha se ampliando desde a década anterior. A implantação do Sistema Único de Saúde embora tenha buscado priorizar os serviços públicos, manteve o modelo de compra de serviços privados para a suplementação de suas atividades ${ }^{18}$. Com a implantação do programa Viva Mulher e a necessidade de leitura de um grande número de lâminas, a compra de exames citológicos se intensificou. Para termos uma

18. O processo de implantação do Sistema Único de Saúde não inibiu as atividades privadas nesse campo. Os serviços privados se mantiveram e em alguns casos até se ampliaram, a partir do fortalecimento dos planos de saúde. Sobre esse tema ver: Bahia, Ligia. A démarche do privado e público no sistema de atenção à saúde no Brasil em tempos de democracia e ajuste fiscal, 1988-2008. In: Matta, Gustavo; França Lima, Júlio, orgs. Estado, sociedade e formação profissional em saúde: contradições e desafios em 20 anos de SUS. Rio de Janeiro: Editora Fiocruz/EPSJV; 2008, p. 123-185. 
dimensão da magnitude desse processo podemos observar que em 2001, dos mais de oito milhões de exames efetuados pelo SUS, 60,3\% foi elaborado por laboratórios privados; em 2002 o número de exames vendidos ao SUS pela iniciativa privada alcançava a cifra de $66,7 \%$ do total efetuado. Corroborando com esses dados, uma pesquisa sobre o perfil dos laboratórios que prestavam serviços ao SUS, utilizando uma mostra de 67,9\% dos laboratórios que efetuavam exames citológicos para a saúde pública em 2002, mostrou que $70,2 \%$ desses estabelecimentos eram privados ${ }^{19}$.

Para garantir a qualidade dos exames efetuados nesses laboratórios o Ministério da Saúde elaborou instrumentos para a aferição da qualidade dos exames. Para tanto, foi encomendado ao Instituto de Metrologia um instrumento para acreditação de laboratórios ao Programa. Em 1988, o Instituto Nacional de Metrologia elaborou em conjunto com as Sociedades Brasileiras de Patologia e Citopatologia um complexo questionário de avaliação para as unidades que prestavam serviços de citologia ao SUS. Posteriormente, novas regulamentações foram criadas pelas sociedades de citologia, no entanto, não há evidências de que tenha havido um real acompanhamento da qualidade desses laboratórios para a participação no programa de screening ${ }^{20}$.

No final do século XX, concomitantemente ao desenvolvimento das campanhas e programas públicos de screening, também vinha ocorrendo uma ampliação do uso do Papanicolaou no âmbito da medicina privada. Esse processo teve como consequência o surgimento de dois regimes diferenciados em relação a prevenção câncer de colo até hoje existentes. O programa nacional de screening (Viva Mulher) é direcionado prioritariamente as mulheres de baixa renda - usualmente atendidas pelo Sistema Único de Saúde. As mulheres de classe média e alta normalmente estão sob a cobertura de seguros saúde privados e acompanhadas por ginecologistas particulares que prescrevem seus preventivos e os enviavam para leitura em laboratórios privados.

19. Os dados referentes ao número de exames efetuados no setor público e privado encontram-se no Departamento de Informática do Sistema Único de Saúde (DATASUS) www.datasus.gov.br. A pesquisa sobre o perfil dos laboratórios que prestavam serviços ao SUS encontrasse em Thuler, Luiz; Zardo, Lucilia; Zeferino, Luiz. Perfil dos laboratórios de citopatologia do Sistema Único de Saúde. Jornal Brasileiro de Patologia Médica Laboratorial. 2007; 43 (2): 103-114.

20. Sociedade Brasileira de Citopatologia, Sociedade Brasileira de Patologia. Lista de verificação para acreditação de laboratórios médicos de citopatologia e/ou patologia cirúrgica especificamente para o Programa Viva Mulher de prevenção do câncer cervico-uterino, 1988. Disponível em: http://citopatologia.org.br/listaver.htm. Acceso em: 20 jun 2012. 
É importante observar que nos anos 1990 ocorreu um grande desenvolvimento da medicina diagnóstica. No Brasil, esse processo foi marcado pela ampliação da atuação de laboratórios privados de auxílio à atividade médica $^{21}$. Muitos deles passaram a produzir exames citológicos para os consultórios e hospitais privados, além de venderem serviços para os planos de saúde privada que também estavam se expandindo no país.

Diferente dos laboratórios públicos criados especialmente para atender aos programas governamentais de screening, os laboratórios privados que atendiam o SUS tinham a citologia como apenas uma de suas atividades e sua dinâmica empresarial fazia com que tivessem como objetivo a diminuição dos custos dos exames para o aumento da lucratividade. Nesses laboratórios, era comum a contratação de técnicos sem a devida qualificação, para a leitura das lâminas. Embora vigesse a exigência de habilitação formal no exame de proficiência da Sociedade de Citopatologia, a inexistência de fiscalização e de reconhecimento oficial da profissão possibilitava que trabalhadores sem a devida qualificação executassem a leitura de lâminas. Pessoas das mais variadas formações aprendiam de maneira informal a atividade, e por ganharem baixos salários, complementavam seu rendimento examinando um número muito elevando de lâminas, muitas vezes fora do ambiente de trabalho. Essa prática, comum ainda hoje, diminuía a qualidade da leitura da lâmina e, consequentemente, a acurácia do exame ${ }^{22}$. Dessa forma, a conformação do mercado de trabalho do citotécnico começava a se mostrar como um entrave à organização da profissão.

Embora o Estado brasileiro tenha promovido iniciativas para a expansão e padronização dos cursos de formação, a organização de trabalho dos laboratórios privados esticava a corda em outra direção. A não formalização da profissão impedia a organização dos citotécnicos em busca de melhores

21. O Cadastro de Laboratórios do Registro Nacional de Patologia tumoral informa a existência de 361 laboratórios de citopatologia no país em 1987. Em 2004 o SUS contabilizava 1075 laboratórios prestando informações sobre exames realizados para a saúde pública. Embora não existam informações sobre a totalidade de laboratórios privados, a cifra de laboratórios prestadores de serviços ao SUS mostra o grande aumento do número desses estabelecimentos. Os dados encontram-se em Thuler; Zardo; Zeferino, n. 19, p. 105.

22. Evaristo, Simone (presidente da ANACITO). Entrevista concedida ao Programa de História oral do projeto História do Câncer no Brasil: atores, cenários e políticas públicas (Casa de Oswaldo Cruz, Fiocruz) em 02/05/2011. Küll, Leda [Coordenadora do Curso de formação de técnicos em nível médio em citopatologia (INCA/Fiocruz)]. Entrevista concedida ao Programa de História oral do projeto História do Câncer no Brasil: atores cenários e políticas públicas (Casa de Oswaldo Cruz, Fiocruz) em 06/04/2011. 
condições de trabalho. Por outro lado, essa falta de organização garantia maior lucratividade aos laboratórios privados.

Além disso, as ações governamentais para a formação dos citotécnicos tinha como base as recomendações da OPAS sobre o número mínimo ideal de exames a serem processados nos laboratórios por ano, pois estudos mostram que a leitura de um grande número de exames por um mesmo laboratório aumenta a qualidade serviço executado. A ampliação desmensurada da oferta de exames citológicos por laboratórios privados, a partir de uma lógica de mercado, impossibilitou a manutenção dessa diretriz. Em pesquisa já citada, Thuler e seus colaboradores mostraram que em 2002, $81 \%$ da mostra de laboratórios por eles analisada processava um número de exames inferior ao recomendado ${ }^{23}$.

Embora a divisão entre o público e o privado fosse um obstáculo a normatização das atividades dos citotécnicos, a questão não se limitava a esse aspecto. Como veremos a seguir, a questão da formalização da profissão do citotécnico iria se ligar a disputa pelo monopólio da supervisão de sua atividade. De forma semelhante à questão da formação, esse problema também se relacionaria ao binômio público privado existente no setor.

\section{Disputas pela supervisão do trabalho}

Ao analisarmos os documentos oficiais do Programa Nacional de Combate ao Câncer de Colo Uterino - Viva Mulher, percebemos que a instituição desse programa trouxe à tona a disputa de mercado existente entre farmacêuticos e médicos citopatologistas e patologistas no campo das análises clínicas.

Ainda na década de 1980, biólogos, farmacêuticos e biomédicos passaram a se mobilizar na defesa da possibilidade de atuarem na supervisão de atividades laboratoriais, em particular na leitura de lâminas citológicas. A busca por essa fatia do mercado de trabalho em saúde sofreu várias críticas dos médicos, que definiram essa atividade como responsabilidade sua. $\mathrm{O}$ centro da questão que se apresentava não dizia respeito a leitura das lâminas de Papanicolaou, mas sim o monopólio do controle de qualidade dessa leitura, ou seja, a revisão de uma parte dos exames negativos realizados a atribuição de laudos dos exames duvidosos e positivos.

23. Thuler; Zardo; Zeferino, n. 19, p. 105. 
Com a implantação do programa nacional de screening de câncer de colo, as questões referentes a competência para a execução e supervisão das leituras das lâminas começaram a se intensificar. Contrário às demandas de diversos profissionais não médicos, o Conselho Federal de Medicina emitiu pareceres reafirmando que a citologia e a patologia eram especialidades médicas $^{24}$. Ao defender a prerrogativa dos médicos citopatologistas e patologistas no campo de análises clínicas, o Conselho Federal de Medicina se opunha a atuação de outros profissionais na administração de laboratórios e, consequentemente, na supervisão do trabalho dos citotécnicos.

Em 1998, foi submetido a consulta pública o «Regulamento Técnico para o funcionamento dos laboratório de citopatologia e histopatologia», no âmbito do Programa Viva Mulher. O documento estabelecia que todos os laudos citológicos deveriam ser assinados por médicos citopatologistas e patologistas e que somente esses poderiam assumir responsabilidade técnica pelo laboratório de citopatologia e / ou histopatologia ${ }^{25}$. Seu oitavo item fazia referência ao controle de qualidade dos serviços prestados. Definia que todo laboratório deveria contar com um sistema de controle de qualidade interno, que deveria, entre outras atribuições, revisar todos os esfregaços suspeitos para neoplasia e reexaminar pelo menos $10 \%$ de todos os casos ginecológicos considerados negativos. No entanto, uma nota sublinhava que:

«Os casos cujo escrutínio foi feito por um médico citopatologista com título de especialista em citopatologista ou médico anátomo-patologista com título de especialista em patologia não estão sujeitos a re-escrutínio» ${ }^{26}$.

Esse documento nos deixa entrever que a leitura da lâmina do $\mathrm{Pa}$ panicolaou era feita também por outros profissionais (técnicos ou não), entretanto, estava previsto que os médicos citopatologistas ou anatomo-patologistas deveriam assumir a responsabilidade pelo laboratório e por cada laudo realizado ali. Dessa forma, afirmava-se que a realização de laudos

24. Conselho Federal de Medicina, Parecer n. 36/1989. http://www.portalmedico.org.br/pareceres/ CFM/1989/36_1989.htm, Conselho Federal de Medicina, Parecer n 37/1989 http://www. portalmedico.org.br/pareceres/CFM/1989/37_1989.htm. Acceso em: 20 jun 2012.

25. Secretária de Vigilância Sanitária do Ministério da Saúde. Portaria n. 505, de 23 de junho de 1998. Consulta pública e Proposta de Regulamento Técnico para funcionamento dos laboratórios de citopatologia e Histopatologia.

26. Secretária de Vigilância Sanitária do Ministério da Saúde, n. 25. 
e a responsabilidade pela supervisão dos laboratórios eram prerrogativas apenas dos médicos e de nenhum outro profissional.

Em 13 de agosto de 1998, o Conselho Regional de Farmácia do Estado de Minas Gerais enviou ao Ministro da Saúde, um documento criticando esse regulamento por conferir ao médico, em caráter de exclusividade, a responsabilidade técnica pela supervisão do laboratório de citopatologia ${ }^{27}$. O documento tomava por base o fato de que o decreto que aprovou a regulamentação do exercício da profissão farmacêutica no Brasil, ainda em 1931, definia como competência dos farmacêuticos as análises reclamadas pela clínica médica ${ }^{28}$. Meio século depois, uma nova legislação teria confirmado essa prerrogativa ${ }^{29}$. Esse último decreto conferia ao farmacêutico a possibilidade de exercer

«a direção, o assessoramento, a responsabilidade técnica e o desempenho de funções especializadas exercidas em órgãos ou laboratórios de análises clínicas ou de saúde pública ou seus departamentos especializados» ${ }^{30}$.

Essa atribuição foi ainda confirmada pelo Conselho Federal de Farmácia, com uma resolução de 1987, que ratificou a competência legal para o farmacêutico executar exames de citologia esfoliativa oncótica e hormonal ${ }^{31}$.

O documento do Conselho Regional de Farmácia de Minas Gerais também justificava a competência do farmacêutico para a referida atividade pela abrangência de sua formação, citando que o currículo mínimo do Curso de Farmácia, estabelecido pela Resolução n. 4, de 11 de abril de 1969, do Conselho Nacional de Educação, que incluía como matérias básicas obrigatórias para a formação do farmacêutico bioquímico: «Analista

27. Conselho Regional de Farmácia do Estado de Minas Gerais. Ofício CJ n. 064/98 BH, 13 de agosto de 1998, referente a Consulta pública baixada pela Portaria n. 505, de 23 de junho de 1998, que institui o Programa de combate ao câncer de colo uterino.

28. Decreto n. ${ }^{\circ} 20.377$, de 08 de setembro de 1931. Aprova a regulamentação do exercício da profissão farmacêutica no Brasil. Disponível em http://www.crf-rj.org.br/crf/legislacao/leis/ legis_pro_20377.asp. Acceso em: 15 jun 2012.

29. Decreto n. 85.878, de 7 de abril de 1981. Estabelece normas para execução da Lei n.` 3.820, de 11 de novembro de 1960, sobre o exercício da profissão de farmacêutico. Disponível em http:// www.crf-rj.org.br/crf/legislacao/leis/legis_pro_85878.asp. Acceso em: 15 jun 2012.

30. Decreto, n. 29.

31. Conselho Federal de Farmácia. Resolução n. ${ }^{0}$ 179, de 18 de março de 1987, (alterada pela Resolução n.o 357 de 20/04/2001 e pela Resolução n. ${ }^{358 / 01)}$. Ratifica a competência legal de o farmacêutico executar exames de Citologia Esfoliativa: Oncótica e Hormonal. Disponível em: www.cff.org.br/userfiles/file/resolucoes/179.pdf 
clínico», «Citologia (exames citológicos de secreções, excreções, exsudatos, transudatos, líquor cefalorraquiano e sangue)», a «Histologia», a «Bioquímica», a «Anatomia», a «Fisiologia» e a «Patologia». Afirmava-se também que, naquele momento, era exigida a disciplina «Citologia clínica» com estágio supervisionado nas Faculdades de Farmácia.

Pelas razões apontadas, o Conselho Regional de Farmácia de Minas Gerais defendia que os farmacêuticos estavam habilitados, tanto quanto os médicos, a assumirem a responsabilidade técnica pelo laboratório de citopatologia. Como conclusão, defendiam

«a pronta e eficaz interveniência desse Ministério [da Saúde], no sentido de reconhecer a capacitação do Farmacêutico para a realização dos exames citológicos, determinando e acolhendo o credenciamento dos laboratórios sob tutela desses profissionais, a fim de que possam engajar-se no Programa, somando esforços e serviços para o pleno êxito da campanha de combate ao câncer de colo uterino» ${ }^{32}$.

Em outubro de 1999, o Ministério da Saúde publicou uma portaria estendendo aos farmacêuticos o direito à leitura dos slides de pap smear e ao controle de qualidade dessa leitura ${ }^{33}$. É interessante notar que embora a questão da supervisão da leitura das lâminas citológicas fosse uma questão mais geral dos farmacêuticos, no sentido de valorizar sua profissão no âmbito das atividades laboratoriais, sua argumentação para inclusão nesse campo se justificava pela possibilidade de contribuir para o controle do câncer cervical no país. Na verdade, por trás dessa afirmação estava a possibilidade de ser remunerado pelo Sistema Único de Saúde pela elaboração de laudos de Papanicolaou. A despeito da competência para a leitura das lâminas se mostrar relevante nesse embate, a questão principal se relacionava ao controle de qualidade, ou seja a releitura das lâminas para controle e a avaliação de casos duvidosos. A possibilidade de exercer essa atividade garantia aos farmacêuticos a coordenação dos laboratórios de citologia, em especial os que prestavam serviço ao SUS.

32. Conselho Regional de Farmácia do Estado de Minas Gerais, n. 27.

33. Ministério da Saúde. Portaria n. 1230, de 14 de outubro de 1999, Diário Oficial n.199E 18/10/1999. 


\section{Qual o grupo certo para o trabalho?}

Os embates entre médicos e farmacêuticos por espaço no campo da análise de exames citológicos iria ganhar novos atores no final do século XX, momento em que os médicos, empreendem uma verdadeira cruzada pela normatização jurídica de suas atividades, com o objetivo de impedir que outros profissionais do campo da saúde dividissem seu mercado de trabalho. O empenho dos médicos, representados pelo Conselho Federal de Medicina (CFM) na promulgação da lei do Ato Médico tomam corpo a partir de 2002, quando o CFM apoiou a elaboração desse projeto de lei para regulamentar a prática da medicina no qual eram definidas as atividades privativas do médico. O primeiro texto desse projeto foi muito criticado por diversos grupos de profissionais de saúde (farmacêuticos, fisioterapeutas, psicólogos, nutricionistas, assistentes sociais, fonoaudiólogos etc) que o consideravam uma limitação de sua autonomia profissional. Um dos pontos polêmicos do projeto era a atribuição exclusiva aos médicos do direito de fazer os diagnósticos das doenças e a prescrição terapêutica ${ }^{34}$.

A controvérsia sobre a lei do ato médico se estende por vários anos. Em 2003, após longos debates em comissões do legislativo, um substitutivo foi aprovado no Senado. Essa formulação, embora mantivesse a essência de normatizar o exercício dos profissionais de saúde a partir do monopólio dos médicos, rejeitava a ampliação da competência do Conselho Nacional Medicina em relação à legislação sobre a atuação de outros grupos profissionais. Essa questão era de grande importância para as outras categorias da saúde que não aceitavam ter a extensão de suas atividades definidas pelo Conselho de Medicina (Projeto Substitutivo n. ${ }^{\circ}$ 25/02). Enviado à Câmara dos Deputados, onde recebeu o número 7.703/2006, o substitutivo passou por diversas mudanças. Somente em 2009, o projeto foi finalmente votado, com um tom muito mais brando, que caracterizava o médico como integrante de uma equipe multiprofissional voltada para a saúde e tipificava as atividades de seu exclusivo direito ${ }^{35}$. Uma das polêmicas desencadeadas

34. Fernandes, Patrícia. Ato médico: visões e reações de uma polêmica contemporânea das profissões da área de saúde no Brasil. Rio de Janeiro: Casa de Oswaldo Cruz / PPGHCS; 2004 (dissertação de mestrado).

35. Enviado para o Senado, o projeto já com um novo texto passou a tramitar na Comissão de Constituição, Justiça e Cidadania, tendo sido aprovado em fevereiro de 2012. O texto precisará passar pelas comissões de Educação e de Assuntos Sociais antes de ir a Plenário. Fernandes, n. 34, p. $42-60$. 
por esse projeto de lei se referiu à realização dos exames citopatológicos e à elaboração dos seus laudos.

Em setembro de 2009, o Conselho Federal de Farmácia publicou um Ofício referente ao projeto de lei do ato médico defendendo que fosse retirado do texto que iria a votação no plenário da Câmara dos Deputados, as referências aos exames citológicos como atividade privativa do médico, argumentando que essa atividade era também de competência dos farmacêuticos. Direito já garantido por lei a esses profissionais ${ }^{36}$.

Em resposta ao texto inicial do projeto de lei do ato médico, os farmacêuticos passaram a sustentar que, de acordo com a literatura internacional sobre o tema, a leitura da lâmina de citologia esfoliativa não era um método diagnóstico, e sim parte de um método de screening de lesões precursoras, portanto, os laudos por eles emitidos não entravam no campo de domínio dos médicos. Após a identificação de uma alteração pré-maligna ou maligna na leitura da lâmina de citologia esfoliativa, o diagnóstico viria em seguida com a análise dos dados clínicos e com a realização de exames complementares como a biopsia e o exame histopatológico ${ }^{37}$.

Assim como os farmacêuticos, biomédicos e biólogos também se mobilizaram para defenderem sua atuação no campo de análises clínicas. Em abril de 2002, o Conselho Federal de Biomedicina publicou uma resolução definindo as responsabilidades profissionais dos biomédicos. Suas atividades foram caracterizadas como procedimentos de apoio ao diagnóstico médico e entre elas foi incluída a responsabilidade técnica pelos exames de citologia oncótica ${ }^{38}$.

No texto do projeto de lei do ato médico, aprovado em outubro de 2009, é possível perceber o resultado das negociações entre esses grupos. No novo texto afirma-se que eram atividades privativas do médico a emissão dos diagnósticos anatomopatológicos e citopatológicos, no entanto, excetuavam-se do rol dessas atividades a realização dos exames citopatológicos e seus respectivos laudos ${ }^{39}$. A utilização do termo «diagnóstico

36. Conselho Nacional de Farmácia. Ofício de 22 de setembro de 2009, referente ao projeto de Lei no. 7703/2006. [Ato Médico] (OF.5255/2009/SEC/CFF)

37. Conselho Nacional de Farmácia, n. 31.

38. Conselho Federal de Biomedicina. Resolução n. 78, de 29 e abril de 2002. Dispõe sobre o ato profissional biomédico, fiscaliza o campo de atividade do biomédico e cria normas e responsabilidade técnica. Disponível em: http://www.crbm1.com.br/resolucao12.asp

39. Projeto de Lei no. 7703/2006. Dispõe sobre o exercício da medicina. Disponível em http://www. camara.gov.br/proposicoesWeb/fichadetramitacao?idProposicao=339409. Acceso em: 15 jun 2012. 
citopatológico» sugere um novo posicionamento dos médicos patologistas e citopatologistas. Mesmo resguardando o direito de outros profissionais, que possuem habilitação legal, de realizarem os exames citopatológicos, os laudos dados por eles são vistos como laudos técnicos e apenas um médico citopatologista ou patologista pode dar um laudo médico, ou seja, um diagnóstico citopatológico.

Em novembro de 2009, a Sociedade Brasileira de Patologia (SBP), com apoio da Associação Brasileira de Anatomia Patológica e Citopatologia e SBC, publicou uma Cartilha intitulada Ato Médico - A lei da regulamentação da medicina e a defesa dos direitos dos cidadãos. Conforme seus organizadores ela foi idealizada para facilitar o entendimento do Projeto de Lei 7703/2006, lei do ato médico, sendo direcionada tanto aos especialistas quanto ao público geral. No texto da cartilha encontramos uma explicação para a definição dos diagnósticos citopatológicos como uma das atividades privativas do médico:

«[os diagnósticos citopatológicos] Estabelecem benignidade ou malignidade e geram condutas terapêuticas específicas; São elaborados dentro de um contexto clínico, exigindo conhecimentos que permitem conferir significado às lesões celulares e/ou teciduais identificadas ao microscópio; A base clínica e científica para formulação de diagnósticos nas áreas da Anatomia Patológica e Citopatologia apenas é oferecida nas escolas de Medicina, na residência e outras pós-graduações médicas; Em todo o mundo ocidental, o exercício pleno da Anatomia Patológica e Citopatologia está restrito aos médicos [...]» ${ }^{40}$.

Além disso, com a cartilha, procurava-se responder ao grande movimento organizado por outros profissionais contra a lei do ato médico, que era acusada de ser uma ameaça a possibilidade de atendimento integral a todo cidadão brasileiro, preconizada pelo SUS. Afirma-se que a lei não desestabilizaria o SUS:

«Com relação aos programas de prevenção de câncer do colo uterino, não haverá impedimento para a participação de profissionais não-médicos na realização dos exames colpocitológicos (Papanicolaou). Ao médico, entre-

40. Sociedade Brasileira de Patologia. Ato médico: a lei da regulamentação da medicina e a defesa dos direitos do cidadão. São Paulo: SBP; 2009, p. 31. A publicação tem versão impressa e online e traz ainda dois artigos especiais com a opinião dos presidentes do Conselho Federal de Medicina e Associação Médica Brasileira. 
tanto, caberá a responsabilidade pelo diagnóstico. As milhares de pacientes do sistema SUS, beneficiadas com os programas de prevenção do câncer do colo uterino não ficarão desassistidas, porque a lei garante que os exames citopatológicos preventivos (Papanicolaou) poderão também ser realizados de forma multidisciplinar, com a participação de médicos e de outros profissionais habilitados para compartilhar esse trabalho» ${ }^{41}$.

A prevenção do câncer cervical seria, portanto, um exemplo de trabalho multidisciplinar, no qual outros profissionais habilitados poderiam realizar os exames citopatológicos em apoio ao trabalho dos médicos, únicos responsáveis pelo diagnóstico citopatológico. No entanto, ao fazerem essa diferença entre laudo técnico e diagnóstico citopatológico, os médicos igualam o trabalho dos outros profissionais envolvidos com a leitura das lâminas e sua supervisão, o que vai de encontro ao interesse de diversas profissões que buscam fatias desse mercado, em especial dos citotécnicos que perdem a especificidade de sua atividade que exercem.

\section{Citotécnicos: um grupo em mobilização}

Como vimos no início do artigo, as primeiras escolas de citologia surgiram na década de 1970 em instituições de saúde federais e estaduais. Devido a complexidade da formação teórico e prática e a necessidade de equipamentos técnicos, microscópios em especial, essas escolas colocavam no mercado de trabalho, a cada dois anos, um pequeno contingente de citotécnicos com sólida formação. Seus alunos normalmente eram selecionados entre técnicos de instituições públicas de saúde com o objetivo de para elas retornarem quando terminasse sua formação. Com a criação do Viva Mulher, e a ampliação da demanda por exames citológicos surgiram novos cursos no âmbito dos centros universitários de saúde e de instituições envolvidas com o controle do câncer.

No Rio de Janeiro, por exemplo, o Instituto Nacional de Câncer transformou o Serviço Integrado Tecnológico em Citologia (SITEC) num grande centro de formação que a cada ano passou a receber alunos enviados pelas secretárias estaduais das diferentes regiões do país para qualificação profissional. Esses profissionais em muito se diferenciavam dos técnicos

41. Sociedade Brasileira de Patologia, n. 35, p. 14. 
de laboratório sem a devida formação, que eram utilizados em serviços de leitura de laminas de diversos laboratórios, e mesmo dos citotécnicos formados em serviço, que obtinham licença para atuarem depois de passarem no teste de proficiência elaborado pela Sociedade Brasileira de Citologia ${ }^{42}$.

No início do século XXI, o INCA passou a ser responsável pela política nacional de atenção oncológica, tendo entre as suas funções, a promoção da educação permanente dos profissionais de saúde e a formação e especialização de recursos humanos. Com base nesse objetivo institucional e partindo do diagnóstico de que a qualidade do Papanicolaou no Brasil não era adequada pela formação e organização profissional desses técnicos, a instituição deu início a algumas investidas no sentido de qualificar os citotécnicos no país ${ }^{43}$. Em 2008, a instituição elaborou um projeto que previa a criação de um curso de atualização para citotécnicos, um seminário sobre os problemas e perspectivas da categoria, a modernização de sua escola de citotécnicos (SITEC), a produção de um estudo nacional sobre essa força de trabalho e ações institucionais para a regulamentação da profissão junto aos setores responsáveis pela gestão de Educação em saúde do Ministério da Saúde. No ano seguinte, o Instituto patrocinou a I Jornada Nacional dos Citotécnicos, um ciclo de palestras onde foram apresentados trabalhos técnicos sobre citologia, discutidos problemas da categoria e propostas para a melhoria da situação. ${ }^{44}$

Em paralelo à jornada dos citotécnicos foi criada uma Associação Nacional de Citotécnicos (ANACITO) com o objetivo de defender os interesses dos citotécnicos e, principalmente lutar pela regulamentação da profissão. As lideranças da associação acreditam que os problemas dos citotécnicos relacionam-se prioritariamente a falta de uma regulamentação formal da profissão o que leva a diversas disparidades nas condições de trabalho e renda desses trabalhadores, como a inexistência e plano de carreira, de-

42. Thuler, Luiz Claudio. A inserção do citotecnologista nas políticas do SUS. Rio de Janeiro: Casa de Oswaldo Cruz; 2009. Arquivo Digital. Palestra proferida na I Jornada Internacional de citotecnologia ocorrida entre 12 e 14 de agosto de 2009; Evaristo, Simone (presidente da ANACITO). Entrevista concedida ao Programa de História oral do projeto História do Câncer no Brasil: atores, cenários e políticas públicas (Casa de Oswaldo Cruz, Fiocruz) em 02/05/2011. Küll, Leda (Coordenadora do Curso de Formação de Técnicos em Nível Médio em Citopatologia (INCA/Fiocruz). Entrevista concedida ao Programa de História oral do projeto História do Câncer no Brasil: atores cenários e políticas públicas (Casa de Oswaldo Cruz, Fiocruz) em 06/04/2011.

43. Thuler, n. 42.

44. Thuler, n. 42. 
finição de carga horária para o trabalho etc. Suas principais bandeiras se relacionam à normatização da quantidade de lâminas a serem examinadas por cada citotécnico em cada jornada de trabalho e a questão da sua formação. Em relação ao primeiro aspecto, justificam que o trabalho exercido ao microscópio é muito minucioso e exige um alto grau de concentração, não podendo ser efetuado durante longas jornadas ou em ambientes inadequados. Por isso, defendem que, de forma semelhante a maioria dos países onde a profissão é regulamentada, é necessário normatizar a quantidade de horas a serem trabalhadas e o número máximo de lâminas a serem lidas a cada jornada de trabalho. No que tange a formação profissional, buscam consolidar a exigência de formação em curso específico, com grade curricular ampla, direcionada ao conhecimento de diversas formas de citologia e com muitas horas de aprendizagem monitorada. Postulam ainda, que de forma semelhante a grande parte dos países europeus e ao Canadá, a formação em citotecnologia no Brasil deveria se dar em nível universitário ${ }^{45}$.

A consecução dos objetivos do INCA e da ANACITO esbarram em problemas de difícil resolução, que envolvem interesses de outros grupos. A existência de citotécnicos sem a devida formação causa uma divisão nos interesses da categoria em relação à normatização da profissão, pois ao mesmo tempo que essa regularização pode vir a melhorar as condições de trabalho dos que tiveram a formação considerada adequada, impede os técnicos sem formação de exercer a atividade. Além disso, a formalização da profissão dos citotécnicos representaria um custo adicional aos laboratórios que utilizam profissionais sem a devida formação para a leitura das lâminas de citologia.

\section{Considerações finais}

Segundo Monica Clarke e Joan Fujimura, uma perspectiva interessante para os estudos sociais das ciências é a análise da trajetória dos instrumentos ao longo do tempo, tendo em vista que:

45. Evaristo, Simone (presidente da ANACITO). Entrevista concedida ao Programa de História oral do projeto História do Câncer no Brasil: atores, cenários e políticas públicas (Casa de Oswaldo Cruz, Fiocruz) em 02/05/2011. Küll, Leda (Coordenadora do Curso de Formação de Técnicos em Nível Médio em Citopatologia (INCA/Fiocruz) Entrevista concedida ao Programa de História oral do projeto História do Câncer no Brasil: atores cenários e políticas públicas (Casa de Oswaldo Cruz, Fiocruz) em 06/04/2011. 
«Tools are not neutral objects but trough their use in practice- in interactive situations - become meaning-laden entities to all those familiar with them for any reason. Moreover, those meanings may differ among the parties involved, leading varyingly to conflict, coexistence, or domination» ${ }^{46}$.

Como afirmam esses autores, esses instrumentos podem estar relacionados a uma disciplina ou podem atravessar diferentes disciplinas. No caso aqui analisado, é possível perceber que a disputa de mercado entre profissionais de nível superior faz com que o teste de Papanicolaou seja acionado de diferentes formas nos discursos produzidos por esses grupos para defenderem sua participação em ações de controle do câncer cervical no Brasil.

Trabalhos anteriores demonstraram que a definição do teste Papanicolaou como a ferramenta de screening ideal para a prevenção do câncer cervical não significou que essa tecnologia tenha se estabilizado e se transformado em «caixa-preta» ${ }^{47}$. Ao contrário, segundo esses estudos, essa tecnologia esteve em constantemente negociação, aspecto que não faz com que ela fosse vista como menos eficaz. Isso porque a própria ambiguidade e instabilidade da tecnologia sustenta a rede de grupos e instituições que dão sentido aos programas de combate ao câncer cervical. Como demonstrou Monica Casper e Adele Clarke, apesar dos conflitos e dificuldades de padronização dessa tecnologia, a articulação entre grupos e interesses diversos e as transformações decorrentes de sua utilização prática possibilitaram a transformação do teste Papanicolaou em tecnologia perfeita para a realização de campanhas de screening de câncer cervical (the right tool for the job). Ao longo do tempo, o objetivo inicial de utilização do teste Papanicolaou como tecnologia diagnóstica das lesões malignas deu lugar a sua utilização como uma tecnologia de screening que detecta as lesões pré-malignas. E mesmo com as dificuldades de definição e padronização do que são as lesões pré-malignas, que marcaram a história do desenvolvimento dessa tecnologia, ela se difundiu e «the Pap smear became gradually perceived as a prescreening rather than a true diagnostic test ${ }^{48}$.

\footnotetext{
46. Clarke; Fujimura, n. 4, p. 16.

47. Casper; Clarke, n. 1, p. 255-290; Lowy, n. 1, p. 53-67; Singleton, Vicky. Stabilizing instabilities: The role of the laboratory in the United Kingdom Cervical Screening Programme. In: Berg, Marc; Mol, Annemarie, eds. Differences in medicine: Unraveling practices, techniques and bodies. Durham: Duke University Press; 1988, p. 86-105.

48. Lowy, n. 1, p. 60.
} 
Os debates sobre quem tem a prerrogativa para fazer as análises clínicas e para supervisionar o trabalho dos citotécnicos no Brasil trazem a luz a instabilidade dessa tecnologia. Nesse debate é possível perceber a utilização por esses grupos de termos como laudo técnico ou laudo médico e exame citopatológico por diagnóstico citopatológico quando defendem sua participação em ações para a prevenção de câncer cervical. Como vimos, a proposta dos médicos citopatologistas de diferenciarem o laudo técnico do diagnóstico citopatológico dificulta ainda mais o processo de normatização da atividade dos citotécnicos, pois iguala o trabalho dos outros profissionais de nível superior (como farmacêuticos e biomédicos) ao trabalho desses profissionais de nível médio.

Além disso, como também observamos, a lógica privada dos laboratório, tanto no que se refere a contratação de seus quadros profissionais, como no que concerne ao modelo de produção e venda de serviços, dificulta a organização dos citotécnicos ao mesmo tempo que impede a racionalização do setor. Dessa forma, é possível afirmar que a busca do Estado, por meio do INCA, de qualificar melhor os citotécnicos e regulamentar sua profissão tem como limites a dinâmica de um mercado de saúde formatado de acordo com interesses profissionais específicos e os valores referentes ao mix público e privado existente no setor. Num contexto onde a utilização do Papanicolaou responde simultaneamente a demandas de um sistema público de saúde em busca de racionalização técnica para atender a um programa nacional de screening e ao interesse do mercado, a profissão do citotécnico caminha na corda bamba.

\section{Agradecimentos}

Gostaríamos de expressar nosso reconhecimento a Eliane Monteiro Santana Dias pelo auxílio na apresentação das fontes. 